\title{
Hepatitis C in Dialysed Patients - What Is the Current Optimal Treatment?
}

\author{
Petar Kes Nikolina Basic-Jukic \\ Department of Dialysis, Zagreb University Hospital Centre, Zagreb, Croatia
}

\section{Key Words}

Hepatitis C - End-stage renal disease - Dialysis •

Interferon alfa $\cdot$ Peginterferon $\cdot$ Ribavirin

\begin{abstract}
Hepatitis C virus (HCV) infection is an important cause of morbidity and mortality in the dialysis population. The problem is more pronounced after renal transplantation. It seems that immunosuppressive drugs facilitate HCV replication and accelerate hepatic lesions. Interferon is not recommended after renal transplantation because of the risk of acute rejection and graft dysfunction, and for this reason it is important to eradicate HCV RNA before transplantation. Prevention is the most important treatment measure. Good clinical practice together with screening of blood products and organs is of outstanding importance. Pegylated interferon (PEG-INF) and ribavirin are currently considered to be optimal therapy for HCV infection. Pegylation delays clearance of interferon, which leads to a more potent and longer antiviral effect. The two PEG-INF formulations (alfa-2a and alfa-2b) with different pharmacokinetic characteristics are currently available. Their clearance is reduced by almost $45 \%$ in patients with end-stage renal disease. Taken together with the high prevalence of adverse effects associated with
\end{abstract}

This invited review was supported by an unrestricted educational grant provided by Amgen.

\section{KARGER \\ Fax +41613061234 E-Mail karger@karger.ch} www.karger.com

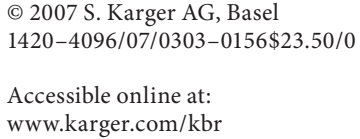

the PEG-INF, an increased awareness of their use in dialysis patients is reasonable. There are few published studies on interferon and PEG-INF therapy in uremic patients. These studies confirm that the rate of response to different interferon formulations in dialysis is much higher than in the general population, but with a higher rate of adverse events. Ribavirin increases the response rate to treatment with PEGINF. Great caution is warranted on its use in dialysis patients, whereas in patients with renal disease it accumulates and causes a dose-related haemolysis. Current results are encouraging but limited by a small number of patients and short follow-up. Multi-centre, controlled studies with longer follow-up are needed to establish an optimal protocol for the treatment of chronic HCV infection in dialysis patients.

Copyright $\odot 2007$ S. Karger AG, Basel

Hepatitis $\mathrm{C}$ virus (HCV) infection is a common problem in dialysis patients with the prevalence ranging from 1 to $63 \%$ [1]. HCV transmission occurs mainly through exposure to infected blood. Infection may spread through contaminated haemodialysis equipment or unsafe medical practices. Patient-to-patient transmission of $\mathrm{HCV}$ with transplanted organ has been reported. Although previous reports have suggested a benign clinical and histological course of HCV infection in dialysis patients, current investigations demonstrate all grades of chronic hepatitis including liver cirrhosis [2]. HCV infection has been identified as an important cause of morbidity and

Petar Kes, MD, PhD

Department of Dialysis, Zagreb University Hospital Centre

Kispaticeva 12

HR-10000 Zagreb (Croatia)

Tel. +385 16682 616, Fax +385 12312 517, E-Mail kespetar@net.hr 
mortality in dialysis patients [3]. Hepatitis C-positive recipients have an increased risk of chronic liver disease and mortality after renal transplantation compared with HCV-negative patients [4]. According to the results of Pedroso et al. [5], HCV infection adversely affects patient and graft survival and increases the risk of death from infections. Interferon is not recommended after renal transplantation because of the risk of acute rejection and graft dysfunction, and for this reason it is important to eradicate HCV RNA before transplantation [6].

This article summarizes the current understanding of $\mathrm{HCV}$ infection in dialysis patients with emphasis on its treatment.

\section{Epidemiology of Hepatitis C in Dialysis Patients}

Long-term kidney disease, multiple blood transfusions and/or organ transplant before 1992 and potential exposure to nosocomial infections in dialysis units make dialysis patients especially vulnerable to the development of hepatitis $\mathrm{C}$ and other blood-borne infections. There is substantial variability in the prevalence of chronic HCV infection among dialysis patients worldwide. Lower socioeconomic status of the country has been associated with an increased prevalence of HCV infection, mainly due to insufficient resources for treatment with erythropoietin and for maintenance of dialysis units. In the era of screening tests that exclude infected blood or donors, $\mathrm{HCV}$ is rarely transmitted by blood transfusion or transplantation. However, despite all these advances, HCV infection remains a significant problem even in industrialized countries [1]. Dialysis units with an increased prevalence of HCV also have an increased incidence of the infection. Strategies to control nosocomial transmission of HCV should be implemented in all dialysis units. Besides standard universal precautions like the use of gloves and restricted use of common supplies, special attention should be focused on careful disposal of dialysers and blood tubing after haemodialysis sessions. Strict isolation of HCV-positive patients is usually not recommended. However, it might be a useful measure for prevention of nosocomial spread of HCV in dialysis units with a high $\mathrm{HCV}$ prevalence [7]. Available data demonstrate that patients with $\mathrm{HCV}$ infection may be included in dialyser reuse programs. Patients should be regularly monitored. In Croatia, all dialysis units test their patients and staff for anti-HCV. Surprisingly, only $62 \%$ of the centres in the USA have introduced routine testing for $\mathrm{HCV}$ in dialysis patients [1]. In the 9-year study of 6,412 patients starting dialysis in Italy, Di Napoli et al. [8] found a decrease in anti-HCV prevalence from 30.6 to $15.1 \%$ that could be related to the higher mortality of $\mathrm{HCV}$-positive patients compared with HCV-negative subjects.

\section{Natural History of HCV Infection in Dialysis Patients}

The natural history of HCV in dialysis patients is not completely understood. The reduced long-term survival combined with slow progression of the $\mathrm{HCV}$-associated liver disease may mask the consequences of HCV infection in the dialysis population. Reports on the natural history of hepatitis $C$ infection in the dialysis population vary. Previous studies that focused on liver disease demonstrated a low proportion of HCV-positive dialysis patients with bridging hepatic fibrosis or cirrhosis. In a multi-centre prospective study, Nakayama et al. [9] demonstrated an increased risk of death in HCV-positive patients due to cirrhosis and hepatocellular carcinoma. Okuda and Yokosuka [10] compared $189 \mathrm{HCV}$-positive dialysis patients with 378 sex-/age-matched controls without uraemic syndrome. Of 25 dialysis patients who were followed up for more than 15 years, 15 patients were HCV RNA negative. None of them progressed to cirrhosis. During the same period none of the controls had lost HCV RNA, and one quarter to one third of them progressed to cirrhosis. The possible explanation for such a distinct difference is reduction of the viral load via adsorption of viral particles onto the dialyser membrane with their subsequent destruction [10]. Badalamenti et al. [11] observed an increased level of circulating interferonalfa after HD sessions. They suggest lymphomonocyte activation as an additional mechanism for the mild course of hepatitis $\mathrm{C}$ in dialysis patients.

\section{Diagnostic Approach}

Various tests are available for the diagnosis and followup of HCV infection. Serological tests of the third generation are highly sensitive and specific, and are suitable for screening of dialysis patients. False-negative tests are nowadays rare, while false-positive tests may occur in dialysis patients with autoimmune disorders or other infections. Confirmation of HCV infection is obtained by qualitative or quantitative HCV RNA assay. ALT is a helpful although non-specific marker of the presence of $\mathrm{HCV}$ infection in the dialysis population. Serial determinations of ALT imprecisely reflect the severity of liver 
disease and do not correlate with the liver histology or viral load. Only liver biopsy provides information on the extent of HCV-associated liver disease. This invasive procedure is associated with an increased risk of bleeding in dialysis patients. Transjugular biopsy is associated with a lower risk, and nowadays liver biopsy seems mandatory to evaluate the severity of liver disease in order to choose the most suitable treatment option $[6,12]$.

According to our experience, all patients with endstage renal disease (ESRD) should be screened for HCV with serological test before starting renal replacement therapy. In case of positive serology, viral load should be determined by HCV RNA. In addition, qualitative HCV RNA should be determined at least once in each patient to discover patients that have 'escaped' lower-sensitivity tests.

\section{Treatment of HCV Infection in Dialysis Patients}

The most important treatment option is prevention of infection. Elimination of the virus from the infected host is a difficult task. According to the current knowledge, interferon therapy is considered as the main treatment option in all patients with $\mathrm{HCV}$-infection associated liver disease. Despite the fact that $\mathrm{HCV}$ infection adversely affects the survival of dialysis and renal transplant patients and its high prevalence in these groups of patients, large clinical trials are lacking.

\section{Interferon Alfa}

Interferon alfa is a non-glycosylated serum protein that is induced by exposure to foreign antigens. After filtration at the glomerulus, interferon alfa is reabsorbed in proximal tubules where it undergoes proteolytic degradation. Elimination half-life of interferon alfa is increased in patients with renal failure. Several interferon-alfa formulations have been developed for therapeutic use in humans (alfa-2a, alfa-2b, alfa-n1).

The optimal treatment protocol for interferon monotherapy in $\mathrm{HCV}$-positive dialysis patients remains unclear. Fabrizi et al. [13] evaluated 14 clinical trials and demonstrated that more than $37 \%$ of HCV-positive dialysis patients may be successfully treated by interferon monotherapy. Sustained virological response (SVR) defined as undetectable HCV RNA at 6 months after treatment was achieved by only $7-16 \%$ of patients with chronic HCV infection and normal renal function [14]. Better therapeutic response may be explained by lower viral load in uraemic patients, alterations in the pharmacoki- netics of interferon in renal failure, and possibly by improvement of the immune response in dialysis patients induced by interferon.

Adverse events were not only more common but also more severe in dialysis patients. Besides pancytopenia, flu-like syndrome, neurological disorders and gastrointestinal problems, severe side effects included cerebral haemorrhage, pulmonary oedema, acute pancreatitis and cardiomyopathy [13]. The drop-out rate was 17\% [13], compared to $5-9 \%$ in patients with normal renal function [14]. Drug accumulation, comorbidities and advanced age may enhance toxicity and explain the lower tolerance of interferon in dialysis patients.

Grgurević et al. [15] evaluated two different therapeutic protocols for dialysis patients: 8 patients were treated with INF-alfa $3 \times 3 \mathrm{MU} /$ week s.c. for 6 months (group A), and 7 patients were treated with INF-alfa $3 \times 5 \mathrm{MU} /$ week for 3 months, then $1 \times 5 \mathrm{MU} /$ week for another 3 months (group B). The end of treatment response was $87.5 \%$ in group A and $28.5 \%$ in group B, the difference being statistically significant $(\mathrm{p}<0.05)$. Although better SVR (50 vs. $28.5 \%$ ) and lower drop-out rate (0 vs. $28.5 \%$ ) were achieved in group A compared to group B, these differences did not reach statistical significance [16]. Therapy with INF-alfa $3 \times 3 \mathrm{MU} /$ week s.c. for 6 months seems to be more appropriate for the treatment of HCV in dialysis patients, mostly due to better tolerability, i.e. lower drop-out rate. These differences could be attributed to different pharmacokinetic properties of the particular therapy protocol. Urbanek et al. [17] demonstrated that early diagnosed HCV infection in dialysis patients could be more efficiently treated than chronic infection. $\mathrm{Pa}-$ tients were treated with INF-alfa 2B $10 \mathrm{MU}$ administered daily for 21 days followed by $3 \mathrm{MU}$ administered 3 times weekly for 12 weeks. They obtained a SVR in $72 \%$ of patients without any serious side effects of treatment.

\section{Pegylated Interferon}

Modification with polyethylene glycol (PEG) reduces clearance of interferon. Two formulations of PEG-interferon (PEG-INF) have been developed: (1) pegylated interferon alfa-2a (PEG-INF alfa-2a), obtained by conjugation of a $40-\mathrm{kDa}$ branched PEG polymer to lysine residues to interferon alfa-2, and (2) pegylated interferon alfa-2b (PEG-INF alfa-2b) with a single $12-\mathrm{kDa}$ linear moiety attached to interferon alfa-2b [17]. While PEG-INF alfa-2b is cleared by the kidneys, PEG-INF alfa-2a is metabolized in the liver. The PEG moiety is inert and is removed from the body in 50-60 days. Different pharmacokinetic parameters (table 1) result in different timing of the occur- 
rence of adverse effects. Alfa-2b peginterferon is associated with a rapid onset of side effects. Side effects of alfa$2 \mathrm{a}$ peginterferon gradually increase during the first several weeks of treatment [18].

Pharmacokinetic studies in dialysis patients have shown marked elevation of blood levels of PEG-INF alfa$2 \mathrm{~b}$, but not of PEG-INF alfa-2a. Clearance fraction of PEG-INF alfa-2a decreased from $94 \mathrm{ml} / \mathrm{h}$ in controls to $63 \mathrm{ml} / \mathrm{h}$ in ESRD patients, increasing its half-life from 52 to $58 \mathrm{~h}$ [19]. A dose of $135 \mu \mathrm{g}$ PEG-INF alfa-2a in ESRD patients resulted in similar serum levels as a dose of 180 $\mu \mathrm{g}$ in patients without renal failure. A weekly dose of $0.5-$ $1.0 \mu \mathrm{g} / \mathrm{kg}$ of PEG-INF alfa-2b has been suggested for $\mathrm{pa}-$ tients with ESRD [6].

Clearance of PEG-INF alfa-2a and PEG-INF alfa-2b may differ depending on the pore size of dialysers. A 40kDa PEG-INF alfa-2a was not cleared through dialysers with pore sizes $<100 \AA$ A In contrast, PEG-INF alfa-2b was cleared through dialysers with pore sizes $>60 \AA$ A. These results suggest the possibility to improve the efficacy of PEG-INF treatment with the use of appropriate dialysers. This issue needs confirmation by in vivo studies [20].

Pegylated interferons have been more efficient in treatment of chronic HCV infection than standard interferons [21]. However, data on the efficacy and safety of peginterferons in the dialysis population are limited (table 2).

Sporea et al. [22] used $180 \mu \mathrm{g}$ of PEG-INF alfa-2a for 48 weeks in $10 \mathrm{HCV}$-positive dialysis patients. The dropout rate was $40 \%$. Two patients stopped treatment because of non-compliance, 1 patient died from cerebral haemorrhage, and 1 patient developed sepsis secondary to central venous catheter insertion. Three of $6(50 \%)$ patients that completed the 48 -week treatment had a SVR. However, the intention-to-treat analysis showed SVR in only $30 \%$ (3 of 10) of patients. All patients experienced side effects related to the use of PEG-INF, without the need to discontinue the treatment [22]. Annicchiarico and Siciliano [23] report the results of their study in which 6 patients received PEG-INF alfa-2b for 24 weeks. SVR was $33 \%$. Teta et al. [24] treated 3 patients with PEGINF alfa-2a. The starting dose of $180 \mu \mathrm{g} /$ week was reduced in 2 patients because of cytopenia and other side effects (insomnia, depression, weight loss, flu-like symptoms and cutaneous bullous lesions). They completed their treatment with a weekly dose of $90 \mu \mathrm{g}$. Recently, Kokoglu et al. [25] prospectively followed up 12 patients who received $135 \mu \mathrm{g}$ of PEG-INF alfa-2a weekly for 48 weeks. All patients were interferon naive. Another $13 \mathrm{di}-$ alysis patients with HCV infection served as controls. End-of-treatment virological responses were $83.4 \%$ in the treatment group and $7.7 \%$ in the control group. SVR was achieved by 75 and $7.7 \%$ of patients, respectively. These results are encouraging. Although all patients experienced adverse effects related to PEG-INF, they completed their 48-week treatment. The most common side effects included anaemia, fatigue, thrombocytopenia and leucopoenia [25]. Covic et al. [26] published in 2006 results of treatment of 78 dialysis patients with PEG-INF alfa-2a. An early viral response was obtained in $61.5 \%$ of patients. However, a high rate of non-compliance and adverse

Table 1. Pharmacokinetic parameters of two PEG-INF alfa formulations

\begin{tabular}{lll}
\hline Parameter & $\begin{array}{l}\text { PEG-INF } \\
\text { alfa-2a }\end{array}$ & $\begin{array}{l}\text { PEG-INF } \\
\text { alfa-2b }\end{array}$ \\
\hline Clearance, $\mathrm{ml} / \mathrm{min}$ & 725 & 60 \\
Absorption half-life, $\mathrm{h}$ & 4.6 & 5.0 \\
Elimination half-life, $\mathrm{h}$ & 20 & 80 \\
Time to peak serum concentration, $\mathrm{h}$ & 20 & 80 \\
\hline
\end{tabular}

Table 2. Trials with pegylated interferon alfa-2a in dialysis patients with chronic HCV infection

\begin{tabular}{lcllllll}
\hline $\begin{array}{l}\text { Group } \\
\text { (first author) }\end{array}$ & Patients & $\begin{array}{l}\text { PEG-INF } \\
\text { type }\end{array}$ & $\begin{array}{l}\text { Dose } \\
\mu \mathrm{g} / \text { week }\end{array}$ & $\begin{array}{l}\text { Duration } \\
\text { weeks }\end{array}$ & $\begin{array}{l}\text { ETR } \\
\text { rate }\end{array}$ & $\begin{array}{l}\text { SVR } \\
\text { rate, \% }\end{array}$ & $\begin{array}{l}\text { Drop-out } \\
\text { rate, \% }\end{array}$ \\
\hline Sporea, 2006 [22] & 10 & Alfa-2a & 180 & 48 & 87.5 & 30 & 40 \\
Teta, 2005 [24] & 3 & Alfa-2a & 180 & $24-48$ & 67 & 67 & 0 \\
Kokoglu, 2006 [25] & 12 & Alfa-2a & 135 & 48 & 83.4 & 75 & 0 \\
Covic, 2006 [26] & 78 & Alfa-2a & 135 & 48 & 19.2 & 14.1 & 73.1
\end{tabular}

PEG-INF = Pegylated interferon; ETR rate $=$ end-of-treatment response rate (absence of HCV RNA at the end of treatment); SVR rate = sustained virological response (absence of HCV RNA 6 months after stopping therapy). 
events caused discontinuation of therapy in $73.1 \%$ of patients. Thus, only 21 patients reached week 48 on therapy, and only $19.2 \%$ of the initial intention-to-treat population had undetectable HCV RNA levels. Sustained viral response was recorded in only 11 patients (14.1\%). These results are not encouraging, and they do not support the superiority of PEG-INF alfa-2a monotherapy. A large multi-centre study of PEG-INF treatment in dialysis patients has started in the USA [6].

\section{Interferon and Ribavirin}

The combination of PEG-INF and ribavirin is now the standard treatment for patients with chronic hepatitis $\mathrm{C}$ and normal renal function. Ribavirin is cleared predominantly in the kidneys and causes a dose-related haemolysis. Haemodialysis does not change its serum concentration, thus ribavirin is considered to be contraindicated in patients with renal failure who are especially vulnerable to its toxic effects due to pre-existing anaemia and low-grade haemolysis associated with renal failure and dialysis [6].

Several small studies of ribavirin therapy in patients with renal failure have been published. A preliminary report by Tan et al. [27] who treated 5 patients with interferon alfa- $2 \mathrm{~b}$ and ribavirin describes the high incidence of side effects with a drop-out rate of $40 \%$. Four patients developed virological response during the treatment. Bruchfeld et al. [28] treated 6 ESRD patients with interferon alfa- $2 \mathrm{~b}$ and ribavirin. Ribavirin was regularly monitored and the dose adjusted to achieve serum concentrations of $10-15 \mu \mathrm{mol} / \mathrm{l}$. Five patients achieved an end-oftreatment virological response. SVR occurred in only 1 patient. Adverse effects were common despite the use of erythropoietin. The same group investigated the efficacy and safety of pegylated interferon in combination with ribavirin in dialysis patients [29]. Six haemodialysis pa- tients were treated with PEG-INF alfa-2a $135 \mu \mathrm{g} /$ week $(\mathrm{n}=2)$ or PEG-INF alfa-2b $(50 \mu \mathrm{g} /$ week $)(\mathrm{n}=4)$ for 24 (genotype 2) to 48 (genotypes 1 and 4) weeks with the ribavirin dose modified according to plasma concentration. Anaemia was treated with iron and high doses of erythropoietin. All patients achieved virological and biochemical response. SVR was achieved in $3(50 \%)$ patients. Adverse events were quite frequent. One young patient died from heart failure associated with severe coronary atherosclerosis. Anaemia was treated with iron and high doses of erythropoietin. No blood transfusions were necessary [29].

These results indicate that ribavirin can be used for treatment of chronic HCV infection in dialysis patients but with extreme caution and only in strictly controlled clinical trials. Erythropoiesis should be appropriately supported. Preliminary reports indicate that it may be necessary to evaluate cardiovascular status before treatment [29]. It is probable that patient who died while treated with PEG-INF and ribavirin [29] had pre-existing significant coronary atherosclerosis, which is no surprise despite his age, as he had been on dialysis for 12 years.

\section{Conclusion}

Pegylated interferons are the mainstay of therapy for chronic hepatitis C. Currently available data on using PEG-INF in patients with ESRD are contradictory. However, treatment results seem better than those achieved by patients with chronic $\mathrm{HCV}$ infection and normal renal function. Use of ribavirin should still be limited to clinical studies. Results obtained in recent clinical trials should be confirmed by large prospective, multi-centre studies.

\section{References}

1 Tokars JI, Finelli L, Alter MJ, Arduino MJ: National surveillance of dialysis-associated diseases in the United States. Semin Dial 2001;17:310-319.

2 Glicklich D, Tuang SN, Kapoian T, Tellis V, Reinus JF: Comparison of clinical features and liver histology in hepatitis C-positive dialysis patients and renal transplant recipients. Am J Gastroenterol 1999;94:159-163.

3 Espinosa M, Martin-Malo A, Alvarez de Lara M, Alijama P: Risk of death and liver cirrhosis in anti-HCV-positive long-term haemodialysis patients. Nephrol Dial Transplant 2001;16:1669-1674.

\footnotetext{
4 Fehr T, Ambuhl PA: Chronic hepatitis virus infections in patients on renal replacement therapy. Nephrol Dial Transplant 2004;19: 1049-1053.

5 Pedroso S, Martins L, Fonseca I, et al: Impact of hepatitis $C$ virus on renal transplantation: association with poor survival. Transplant Proc 2006;38:1890-1894.

-6 Meyers CM, Leonard LB, Stehman-Breen $\mathrm{CO}$, Hoofnagle JH: Hepatitis C and renal disease: an update. Am J Kidney Dis 2003;42: 631-657.
}

7 Gallego E, Lopez A, Perez J, et al: Effect of isolation measures on the incidence and prevalence of hepatitis $\mathrm{C}$ virus infection in hemodialysis. Nephron Clin Pract 2006;104: $1-6$.

8 Di Napoli A, Pezzotti P, Di Lallo D, et al: Epidemiology of hepatitis $C$ virus among longterm dialysis patients: a 9-year study in an Italian region. Am J Kidney Dis 2006;48: 629-637.

-9 Nakayama E, Akiba T, Marumo F, Sato C: Prognosis of anti-hepatitis $\mathrm{C}$ virus antibodypositive patients on regular hemodialysis therapy. J Am Soc Nephrol 2000;11:18961902. 
10 Okuda K, Yokosuka O: Natural history of chronic hepatitis $\mathrm{C}$ in patients on hemodialysis: case-control study with 4-23 years of follow-up. World J Gastroenterol 2004;10: 2209-2212.

$\checkmark 11$ Badalamenti S, Catania A, Lunghi G, et al: Changes in viremia and circulating interferon- $\alpha$ during hemodialysis in hepatitis $\mathrm{C}$ virus-positive patients: only coincidental phenomena? Am J Kidney Dis 2003;42:143150 .

-12 Huang CS, Ho MS, Yang CS, Lee CL, Tan LA: Hepatitis C markers in hemodialysis patients. J Clin Microbiol 1993;31:1764-1769.

$\checkmark 13$ Fabrizi F, Dulai G, Dixit V, Bunnapradist S, Martin P: Meta-analysis: interferon for the treatment of chronic hepatitis $\mathrm{C}$ in dialysis patients. Aliment Pharmacol Ther 2003;18: 1071-1081.

- 14 Thevenot T, Regimbeau C, Ratziu V, Leroy V, Opolon P, Poynard T: Meta-analysis of interferon randomized trials in the treatment of viral hepatitis $\mathrm{C}$ in naive patients. J Viral Hepat 2001;8:48-62.

15 Grgurević I, Vince A, Buljevac M, et al: Efficacy if interferon-alfa in the treatment of chronic hepatitis $\mathrm{C}$ in dialysis patients: two therapeutic protocols compared. Nephron Clin Pract 2006;103:c8-c11.
6 Rostaing L, Chatelut E, Payen JL, et al: Pharmacokinetics of $\alpha$-IFN-2b in chronic hepatitis $\mathrm{C}$ virus patients undergoing chronic hemodialysis or with normal renal function: clinical implications. J Am Soc Nephrol 1998;9:2344-2348.

17 Urbanek P, Tesar V, Prochazkova-Francisci E, Lachmanova J, Marecek Z, Svobodnik A: Treatment of early diagnosed HCV infection in hemodialyzed patients with interferon- $\alpha$. Treatment of hepatitis C. Blood Purif 2004; 22:344-350.

18 Foster GR: Review article: pegylated interferons: chemical and clinical differences. Aliment Pharmacol Ther 2004;20:825-830.

19 Fried MW, Shiffman ML, Reddy KR, et al: Peginterferon alfa-2a plus ribavirin for chronic hepatitis C infection. N Engl J Med 2002;347:975-982.

20 Barril G, Quiroga JA, Sanz P, Rodriguez-Salvanes F, Selgas R, Carreno V: Pegylated interferon alfa2a kinetics during experimental haemodialysis: impact of permeability and pore size of dialysers. Aliment Pharmacol Ther 2004;20:37-44.

21 Koksal I: Pegylated interferon for treatment in hemodialysis patients with chronic hepatitis C. J Gastroenterol Hepatol 2006;21:575580.

22 Sporea I, Popescu A, Sirli R, et al: Pegylated interferon alpha-2a treatment for chronic hepatitis $\mathrm{C}$ in patients on chronic haemodialysis. World J Gastroenterol 2006;12:41914194.

23 Annicchiarico BE, Siciliano M: Pegylated interferon-alpha $1 \mathrm{~b}$ monotherapy for haemodialysis patients with chronic hepatitis C. Aliment Pharmacol Ther 2004;20:17.
24 Teta D, Luscher BL, Gonvers JJ, Francioli P, Phan O, Burnier M: Pegylated interferon for the treatment of hepatitis $\mathrm{C}$ virus in haemodialysis patients. Nephrol Dial Transplant 2005;20:991-993.

25 Kokoglu OF, Ucmak H, Hosoglu S, et al: Efficacy and tolerability of pegylated interferon alpha-2a in hemodialysis patients with chronic hepatitis C. J Gastroenterol Hepatol 2006;21:575-580.

26 Covic A, Maftei ID, Mardare NG, et al: Analysis of safety and efficacy of pegylated interferon $\alpha-2 \mathrm{a}$ in hepatitis $\mathrm{C}$ virus-positive hemodialysis patients: results from a large, multicenter audit. J Nephrol 2006;19:794801.

27 Tan AC, Brouwer JT, Glue P, et al: Safety of interferon and ribavirin therapy in haemodialysis patients with chronic hepatitis C: results of a pilot study. Nephrol Dial Transplant 2001;16:193-195.

28 Bruchfeld A, Stahle L, Andersson J, Schvarcz $\mathrm{R}$ : Ribavirin treatment in dialysis patients with chronic hepatitis $\mathrm{C}$ virus infection - a pilot study. J Viral Hepat 2001;8:287-292.

29 Bruchfeld A, Lindahl K, Reichard O, Carlsson T, Schvarcz R: Pegylated interferon and ribavirin treatment for hepatitis $\mathrm{C}$ in haemodialysis patients. J Viral Hepat 2006;13:316321. 